\section{CPS-081 EVALUATION OF THE STANDARD DOSAGE REGIMEN OF VORICONAZOLE IN A PAEDIATRIC AND ADULT POPULATION THROUGH THERAPEUTIC DRUG MONITORING}

${ }^{1} \mathrm{P}$ Boada*, ${ }^{1} \mathrm{P}$ Más-Serrano, ${ }^{2} \mathrm{R}$ Nald-Molina, ${ }^{2} \mathrm{~A}$ Ramon-Lopez, ${ }^{1} \mathrm{~A}$ Raymundo, 'S Bernabeu, ${ }^{1} \mathrm{G}$ Riera, ${ }^{1} \mathrm{~A}$ Pascual, ${ }^{1} \mathrm{M}$ Díaz-González, ${ }^{1} \mathrm{~J}$ Selva. ${ }^{1}$ Hospital General Universitario de Alicante, Pharmacy Department, Alicante, Spain; '2Universidad Miguel Hernandez de Alicante, Pharmacy and Biopharmaceutical Division- Faculty of Pharmacy, Alicante, Spain

\subsection{6/ejhpharm-2019-eahpconf.230}

Background Voriconazole is an antifungal drug used for invasive fungal infection with high pharmacokinetic variability and narrow therapeutic range and, therefore, therapeutic drug monitoring (TDM) is recommended.

Purpose The objective was to evaluate the standard dosage regimen of voriconazole in a paediatric and adult population through TDM.

Material and methods Retrospective observational study (January 2015 and October 2017). Inclusion criteria: adult and paediatric patients treated with voriconazole (oral/intravenous) with at least one trough plasma concentrations (C_trough) of voriconazole at steady state ( $>5$ days) with the standard dosage and without concomitant use of potent inducers or inhibitors. Standard dose was: paediatric $8 \mathrm{mg} / \mathrm{kg}$ IV BID or $9 \mathrm{mg} /$ $\mathrm{kg}$ PO BID, and adult $4 \mathrm{mg} / \mathrm{kg}$ IV BID or $200 \mathrm{mg}$ PO BID. Variables: age, weight, indication (treatment or prophylaxis) and $\mathrm{C}$ trough at steady state. Data was stratified by paediatric and adult patients. Primary outcome was: percentage of patients with C_trough at steady state of voriconazol within the therapeutic range at the standard dose (therapeutic window by indication: treatment: $1-5 \mathrm{mg} / \mathrm{L}$; prophylaxis: $0.5-$ $5 \mathrm{mg})$.

Results A total of 56 patients were included $(26.7 \%$ children and $73.2 \%$ adults). In the paediatric group, the mean age and weight was 6.4 years (95\% CI: 3.9 to 9.0 ) and $25.5 \mathrm{~kg}$ (95\% CI: 16.4 to 34.5 ). The mean age and weight for the adult patients were 61.0 years (95\% CI: 56.4 to 65.6 ) and $69.9 \mathrm{~kg}$ (95\% CI: 65.3 to 74.5$)$. 17.7\% of the patients were treated with voriconazole for prophylaxis and $82.2 \%$ for treatment.

The median C trough in paediatrics was lower than in adults: $0.7 \mathrm{mg} / \mathrm{L}$ (p25-75: 0-5.5) vs $2.5 \mathrm{mg} / \mathrm{L}$ (p25-75: $0.1-$ $8.0)$, respectively $(\mathrm{p}<0.05)$.

$66.7 \%$ and $22 \%$ of patients had infra-therapeutic $\mathrm{C}$ trough in paediatrics and adults $(\mathrm{p}<0.05)$, respectively. However, C_trough above the therapeutic window was similar between groups $(6.7 \%$ of paediatrics and $7.3 \%$ of adults).

Conclusion The $\mathrm{C}$ trough with the standard maintenance dose of voriconazol were within the therapeutic range in only $26.7 \%$ in paediatrics, while in the adult group it was $70.7 \%$. Given the high variability observed in the C_trough, it was necessary to perform TDM at the beginning of the treatment to make an individualised dosage adjustment in both paediatric and adult patients.

\section{REFERENCES AND/OR ACKNOWLEDGEMENTS}

https://www.ema.europa.eu/documents/product-information/ vfend-epar-product-information_es.pdf

No conflict of interest.

\section{CPS-082 NEPHROGENIC DIABETES INSIPIDUS INDUCED BY LIPOSOMAL AMPHOTERICIN B: A CASE REPORT}

${ }^{1} S$ Sadyrbaeva, ${ }^{1}$ B Cancela-Diez*, ${ }^{2} \mathrm{M}$ Sanchez-Argaiz, ${ }^{1} \mathrm{~A}$ Jimenez-Morales. ${ }^{1}$ Virgen de las Nieves University Hospital, Pharmacy, Granada, Spain; ${ }^{2}$ San Agustin Hospital, Pharmacy, Linares Jaen, Spain

\subsection{6/ejhpharm-2019-eahpconf.231}

Background Nephrogenic diabetes insipidus (NDI) results from the inability of the late distal tubules and collecting ducts to respond to vasopressin. The lack of ability to concentrate urine results in polyuria and polidipsia. NDI is almost always drug-induced, however, there are other causes such as electrolyte abnormalities.

Purpose To describe a case of NDI associated with the highdose and long-term use of liposomal Amphotericin B.

Material and methods Data were obtained from electronic medical records. Bibliographic research was conducted to find similar cases. The Nnaranjo algorithm was used to estimate the probability of adverse drug reactions.

Results A 39-year-old man diagnosed with diffuse large Bcell non-Hodgkin lymphoma underwent an allogeneic bone marrow transplant. After 2 months, disease progression was detected, and immunosuppressive treatment was withdrawn and rescue treatment initiated. One month later, the patient was diagnosed with graft-versus-host disease grade III (GVHD). Immunosuppressive therapy was started with cyclosporine, micophenolate, sirolimus, methylprednisolone, and oral and rectal beclametasone. Additionally, meropenem, acyclovir, levofloxacine, cotrimoxazole and caspofungine were used as antimicrobial prophylaxis. During hospitalisation, the patient developed invasive pulmonary aspergillosis with isolations of Aspergillus fumigatus and Aspergillus flavus. The patient was treated with liposomal amphotericin B $6 \mathrm{mg} / \mathrm{kg}(440 \mathrm{mg})$ for 41 days with a cumulative dose reaching $18.04 \mathrm{~g}$. Voriconazol and Posaconazol were discarded because of concomitant treatment with sirolimus and parenteral nutrition respectively. On day 5, the serum potassium level began to decrease achieving $<1.5 \mathrm{mEq} / \mathrm{L}$ and urine output increased $>6 \mathrm{litr} /$ day. The patient was transferred to the medical intensive care unit and treated with vigorous potassium administration. NDI was diagnosed and treated with desmopressin $10 \mathrm{mcg} / 12$ hour nasal drops, hydrochlorothiazide $50 \mathrm{mg} / 24$ hour and spironolactone $50 \mathrm{mg} / 24$ hour. According to the Naranjo algorithm, this event would be classified as a possible reaction because of the temporal correlation between NDI and treatment with liposomal Amphotericin B. Several cases were reported related to NDI induced by Amphotericin $\mathrm{B},{ }^{1}{ }^{2}$ regardless of formulation.

Conclusion It is very important to understand the etiology and symptoms related with nephrotoxicity and NDI. The association of other nephrotoxic drugs and persistent hypokalaemia also contributed to this event.Specific intervention is required to prevent nephrotoxicity in patients receiving Amphotericin B.

\section{REFERENCES AND/OR ACKNOWLEDGEMENTS}

1. Metzger NL, Gill KLV. Nephrogenic diabetes insipidus induced by two amphotericin B liposomal formulations. Pharmacotherapy 2009:29:613-20.

2. Canada TW, Weavind LM, Augustin KM. Possible liposomal amphotericinbinduced nephrogenic diabetes insipidus. Ann Pharmacother 2003;37:70-3.

No conflict of interest. 